\title{
Evaluation of GA Performance in TNEP Considering Voltage Level, Network Losses and Number of Bundle Lines
}

\author{
Meisam Mahdavi ${ }^{1, ~}$, Hossein Haddadian ${ }^{2}$ \\ ${ }^{1}$ Department of Electrical Engineering, São Paulo State University, Ilha Solteira, Brazil \\ ${ }^{2}$ Department of Electrical Engineering, University of Zanjan, Zanjan, Iran \\ Email address: \\ mahdavi@unesp.br(M. Mahdavi),haddadian@znu.ac.ir(H. Haddadian) \\ ${ }^{*}$ Corresponding author
}

\section{To cite this article:}

Meisam Mahdavi, Hossein Haddadian. Evaluation of GA Performance in TNEP Considering Voltage Level, Network Losses and Number of Bundle Lines. International Journal of Discrete Mathematics. Vol. 3, No. 1, 2018, pp. 1-10. doi: 10.11648/j.dmath.20180301.11

Received: March 20, 2018; Accepted: March 30, 2018; Published: May 4, 2018

\begin{abstract}
Many models were presented to solve the static transmission network expansion planning (STNEP) problem by previous research. However, in these models, lines' voltage level and losses were not studied in STNEP. Therefore, in present paper, static transmission expansion planning is investigated by considering lines'voltage, losses and bundles using decimal codification genetic algorithm (DCGA). The DCGA is better than mathematical methodologies to solve large-scale, nonlinear and mixed-integer optimization problems, like the TNEP. The proposed method is tested on the real transmission network of Azarbaijan regional electric company, Iran. The results show that operation costs decreases considerably and the transmission system delivered more safe and reliable electric power to customers if the network losses, voltage levels and the number of bundle lines are considered in transmission expansion planning.
\end{abstract}

Keywords: Bundle Lines, Genetic Algorithms, Transmission Expansion Planning, Voltage Level

\section{Introduction}

Transmission network expansion planning (TNEP) is an important part of power system planning that its main goal is to determine place, time and number of new transmission lines that should be constructed in the network. The network construction and operation costs are minimized in TNEP when technical, economic and reliability constraints were satisfied. TNEP should provide necessary adequacy of the lines in delivering electric power to consumers through the planning horizon [1-4]. Dependency of network expansion cost on the various reliability criteria $[5,6]$ makes difficult calculation of this cost. Transmission network expansion planning generally divided into static and dynamic. Static planning determines place and number of new transmission lines that should be installed in the network up to the planning horizon. If in the static expansion the planning horizon is categorized in several stages we will have dynamic planning $[7,8]$.

Generating plants usually are far from the load centers, so investment cost of transmission network is huge. Thus, the STNEP problem should be evaluated carefully in order to reduce transmission system expansion cost. After 1970 that Garver's paper was published, many papers studied the TNEP problem [9]. Some of these papers like [10-26] are about problem solution method. Some others considered various parameters such as uncertainty in demand [10, 27, 28], uncertainty in fuel price [29], reliability criteria [1, 30 33], line loading [34], adequacy [35], voltage level [36], network losses [37], and bundled conductors [38] to solve this problem. Also, some of them studied simultaneous transmission and generation expansion planning [38]. Recently, different methods such as GRASP [14], Benders decomposition [16], HIPER [19] branch and bound algorithm [40], sensitivity analysis [17], genetic algorithm [1, 2, 13], $[22,26]$, simulated annealing [18] and Tabu search [14] were introduced to solve the STNEP problem. Nevertheless, the role of voltage level in reduction of network losses was not considered in all of them.

In [10], artificial neural network (ANN) proposed to solve the TNEP problem by considering the network losses and 
construction cost of lines. But the role of lines' voltage level and expansion cost of substations were not studied. In [12], the network expansion costs and power flow to the lines were embedded in objective function and optimized simultaneously, but the lines' voltage level, network losses and bundled lines were not included in the problem formulation. The objective function in [41] includes expansion and generation costs and reliability criteria of power not supplied energy. The expansion planning was studied as dynamic without considering network losses. In [19], the Benders hierarchical decomposition approach (HIPER) was proposed to solve STNEP problem. Nevertheless, the non-convexities were not canceled completely and application of this approach to networks with a large number of candidate circuits was time consuming. So, in [15], a heuristic approach, called greedy randomized adaptive search procedure (GRASP) was presented to solve the STNEP problem. GRASP is a useful alternate approach to solve many optimization problems. However, this technique is so time consuming and has some difficulties in pruning by comparison. Therefore, in [40], branch and bound (B\&B) algorithm was proposed to determine the expansion cost in STNEP problem. However, this algorithm has too slow convergence speed and difficult implementation in complex TNEP problems. In [17], sensitivity analysis was proposed to expand transmission network. But, if the number of nodes or candidate lines increases, finding reasonable solutions within short computational time will be very difficult. In [18] simulated annealing (SA) was presented to optimize the investment cost and loss of load in STNEP. Although SA is a robust optimization algorithm, however, computing time increases and quality of solutions is degraded if the number of alternatives to be analyzed increase. However, these papers solved the TNEP problem disregarding voltage level, network losses and bundled lines. Recently, global optimization techniques like genetic algorithm (GA) were proposed to optimize the STNEP problem. These methods are heuristic approaches based on random variation and selection operators. GA is a good method to solve the transmission expansion planning problem.

The role of voltage level and network losses of transmission lines were studied in [42]. It has been shown that network losses are reduced considerably by using higher level of voltage. In [43], a stochastic framework was introduced for multi-objective power system expansion planning considering wind generation, absorption of private investment, and network reliability. Finally, in [44], the multistage transmission and generation expansion planning was formulated considering generation reliability as a mixed integer linear programming (MILP) problem using the Benders decomposition. However, these works did not consider the voltage level and bundle of lines in TNEP formulation.

Thus, in this paper, STNEP problem is solved by considering lines' voltage level, power losses and bundles using DCGA. Moreover, the network losses cost and the expansion cost of substations are included in the objective function. The proposed method is tested on a real transmission network of the Azarbaijan to show the efficiency of the proposed method. This network has been located in northwest of Iran.

This paper is organized as follows: the mathematical model is represented in Section 2. Section 3 describes the proposed solution method. The simulation results are given in Section 4. Finally, in Section 5 the conclusion is presented

\section{Mathematical Formulation of the Problem}

The proposed objective function is defined as follows using DC load flow model to consider lines' voltage level and expansion cost of substations.

$$
\begin{gathered}
C_{T}=\sum_{i, j \in \Omega} C L_{i j} n_{i j}+\sum_{k \in \Psi} C S_{k}+\sum_{i=1}^{N Y} C_{\text {loss }} \\
C_{\text {loss }}=\text { loss } C_{M W h} k_{\text {loss }} 8760 \\
\text { loss }=\sum_{i, j \in \Omega} R_{i j} I_{i j}{ }^{2}
\end{gathered}
$$

Subject to [45]:

$$
\begin{gathered}
S f+g-d=0 \\
f_{i j}-\gamma_{i j}\left(n_{i j}^{0}+n_{i j}\right)\left(\theta_{i}-\theta_{j}\right)=0 \\
\left|f_{i j}\right| \leq\left(n_{i j}^{0}+n_{i j}\right) \overline{f_{i j}} \\
0 \leq n_{i j} \leq \overline{n_{i j}} \\
0 \leq g \leq \bar{g}
\end{gathered}
$$$$
\text { Line_Loading } \leq L L_{\max }
$$

Where, $(i, j) \in \Omega$ and:

$C_{T}$ : Total expansion cost of network

$C L_{i j}$ : Construction cost of each line in branch $i-j$ (it is different for 230 and $400 \mathrm{KV}$ lines).

$C S_{k}$ : Expansion cost of $k^{\text {th }}$ substation.

$C_{\text {loss }}:$ Annual losses cost of network.

Loss: Total losses of network.

$C_{M W h}$ : Cost of one MWh (\$US/MWh).

$k_{\text {loss }}$ : Losses coefficient.

$n_{i j}$ : Number of all new circuits in corridor $i-j$.

$R_{i j}$ : Resistance of branch $i-j$.

$I_{i j}$ : Flow current of branch $i-j$.

$\Omega$ : Set of all corridors.

$\Psi$ : Set of all substations.

$N Y$ : Expanded network adequacy (in year).

$S$ : Branch-node incidence matrix.

$f$ : Active power matrix in each corridor. $g$ : Generation vector. 
$d$ : Demand vector.

$\theta$ : Phase angle of each bus.

$\gamma_{i j}$ : Total susceptance of circuits in corridor $i-j$.

$n_{i j}^{0}$ : Number of initial circuits in corridor $i-j$.

$\overline{n_{i j}}$ : Maximum number of constructible circuits in corridor

$i-j$.

$g$ : Generated power limit in generator buses.

$\overline{f_{i j}}$ : Maximum of transmissible active power through corridor $i-j$ which will have two different rates according to voltage level of candidate line.

Line_Loading: Loading of lines at planning horizon year and start of operation time.

$L L_{\max }$ : Maximum loading of lines at planning horizon year.

The calculation method of $k_{\text {loss }}$ and $C S_{k}$ is given in [42]. In this study, the objective function is different from cost functions in $[1-5,7,10,12-41]$. Also, in the problem constraints, Line_Loading is considered as a new restriction to meet the network adequacy after expansion. It should be noted that $L L_{\max }$ is an experimental parameter that its value is between 0 and 1 and determined with respect to the load growth.

\section{Proposed Method}

The optimization variables of the STNEP problem proposed in this paper are discrete, because the goal is to obtain the number and voltage level of new lines in order to satisfy the required adequacy of transmission network. There are various methods to solve this integer programming problem. In this study, the decimal codification genetic algorithm is used to solve the STNEP problem because of its flexibility and simple implementation. The GA is used to solve practical complex optimization problems such as TNEP using three fundamental operators of reproduction, crossover and mutation. It is a random search method that doesn't need a good initial estimation, because it is corrected in evolutionary process. The number of new transmission lines can be coded as binary or decimal in GA. Although binary codification is more conventional in GA but, here, the decimal codification is used due to avoid coding and decoding of optimization variables and diverge the solutions (production of completely different offspring from their parents). Figure 1 shows a typical chromosome for a network with 4 corridors. In part 1 , each gene includes number of existed circuits (both of constructed and new circuits) in each corridor. Genes of part 2 and part 3 describe voltage levels and number of bundle lines for genes in part 1 .

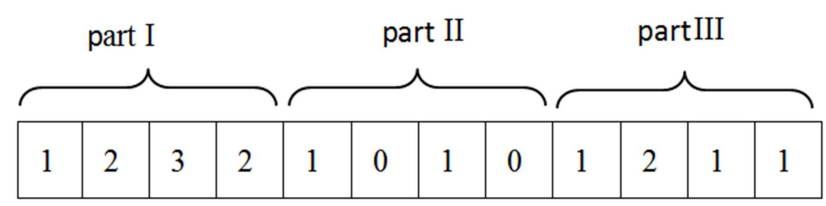

Figure 1. Typical chromosome.
It should be noted that the binary numbers of 0 and 1 were used to represent voltage levels of 230 and $400 \mathrm{kV}$, respectively. In the first corridor, one $400 \mathrm{kV}$ transmission circuit with one bundle, in the second corridor, two $230 \mathrm{kV}$ transmission circuits with two bundle conductors, in the third corridor, three $400 \mathrm{kV}$ transmission circuit with one bundle conductor and finally in the fourth corridor, two $230 \mathrm{kV}$ transmission circuit with one bundle conductor were proposed. The flowchart of the proposed DCGA based method to solve the STENP problem is illustrated in Figure 2.

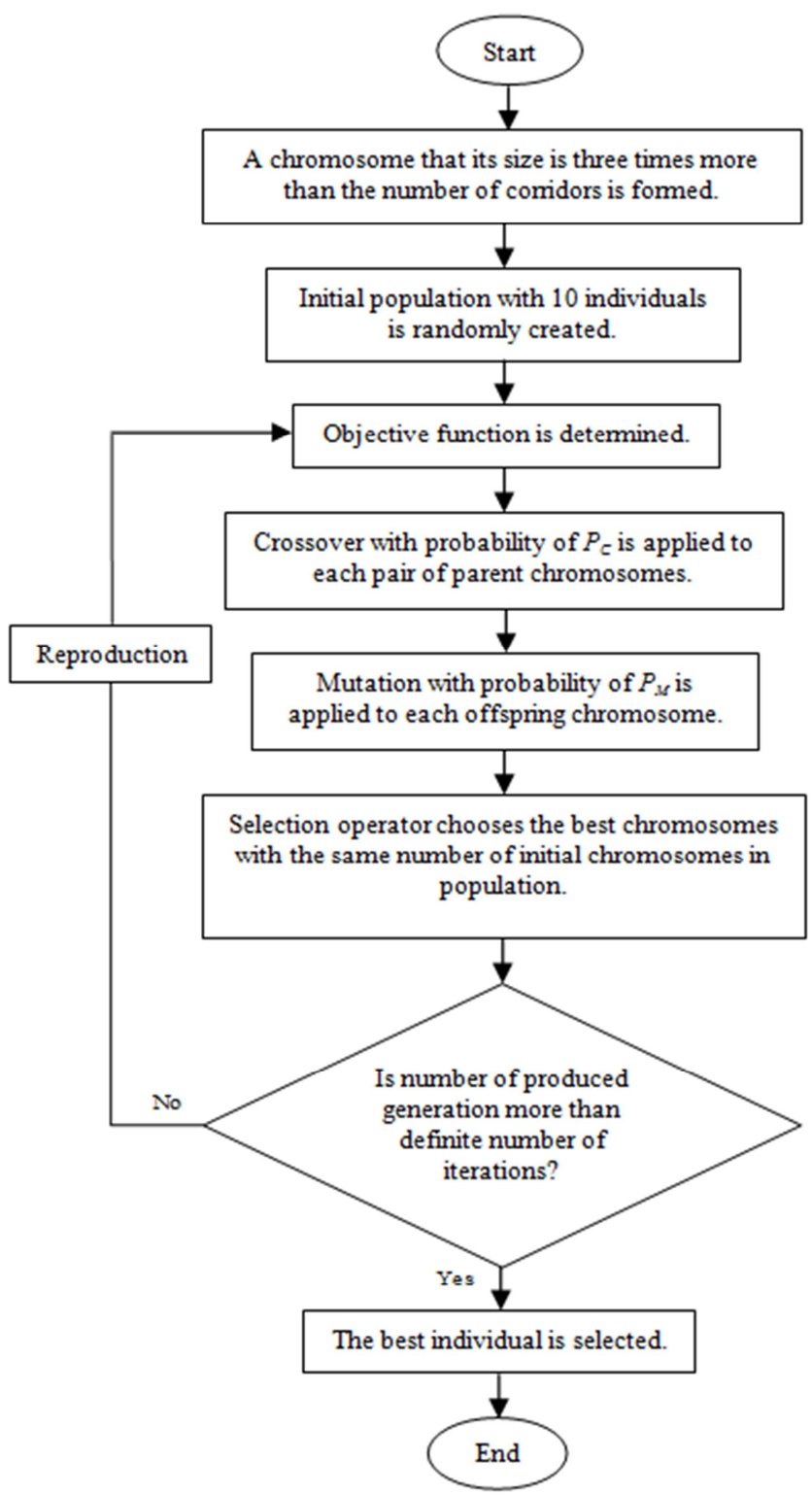

Figure 2. Flowchart of the DCGA.

Then, selection operator based on roulette-wheel selects the parent chromosomes for reproduction. This strategy causes more fit strings to select with a greater probability for forming the next generation. After selection of the pairs of parent strings, the crossover operator is applied to each of these pairs. In this method crossover randomly takes place at the boundary of two integer numbers with probability of 1 
$\left(P_{C}=1\right)$. Then, two chromosomes of each pair swap their genes. Each children resulting from crossover is now subjected to the mutation. This operator selects one of existed integer numbers in chromosome with probability of 0.01 $\left(P_{M}=0.01\right)$ and then changes its value randomly by increasing or decreasing the gene value by 1 . Afterward, reproduction operator reproduces each chromosome with respect to the value of its objective function. The production of new generation is completed and the process all over again with fitness evaluation of each chromosome. The process is terminated by setting a definite number of iterations (generations). In this paper, the definite number of iterations is considered to be 1500 .

\section{Simulation Results}

As it mentioned earlier, the transmission network of the Azarbaijan [46] is used to test the proposed method. This actual network has been located in northwest of Iran and is shown in Figure 3. The system data is given in Appendix A. The proposed method was applied to the test system and the results are given as follows. Also, to verify and prove the stability and robustness of proposed method, the proposed algorithm was performed with different three runs (Run 1, 2 and 3). In all three runs, the planning horizon year is 10 .

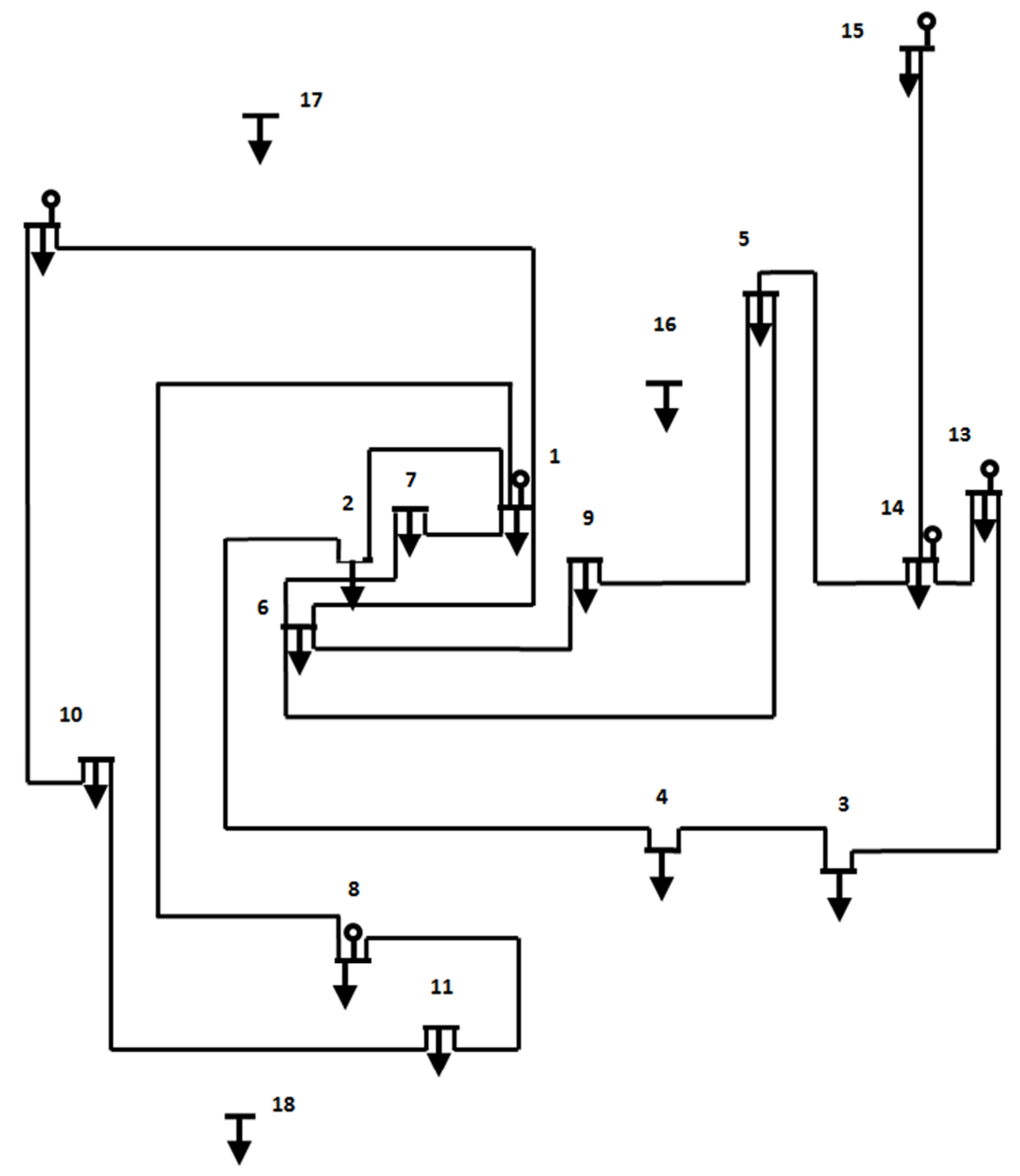

Figure 3. Transmission network of the Azarbaijan.

Run 1

The results of run 1 (lines which should be added to the network up to the planning horizon year) are given in Tables 1 and 2. Also, Tables 3 and 4 show the expansion costs. The first and second configurations are obtained ignoring and considering the network losses, respectively.
Table 1. First configuration: without the losses.

\begin{tabular}{llll}
\hline Corr. & Voltage $(\mathbf{k V})$ & $\begin{array}{l}\text { Number of new } \\
\text { circuits }\end{array}$ & $\begin{array}{l}\text { Number of bundled } \\
\text { conductors }\end{array}$ \\
\hline $8-9$ & 230 & 1 & 1 \\
$2-7$ & 230 & 1 & 1 \\
$1-5$ & 230 & 2 & 2 \\
\hline
\end{tabular}




\begin{tabular}{llll}
\hline Corr. & Voltage (kV) & $\begin{array}{l}\text { Number of new } \\
\text { circuits }\end{array}$ & $\begin{array}{l}\text { Number of bundled } \\
\text { conductors }\end{array}$ \\
\hline $8-18$ & 230 & 1 & 1 \\
$5-7$ & 230 & 1 & 1 \\
$7-16$ & 230 & 1 & 1 \\
$3-6$ & 230 & 1 & 1 \\
$7-17$ & 230 & 1 & 1 \\
\hline
\end{tabular}

Table 2. Second configuration: with the losses.

\begin{tabular}{llll}
\hline Corr. & Voltage $\mathbf{( k V )}$ & $\begin{array}{l}\text { Number of new } \\
\text { circuits }\end{array}$ & $\begin{array}{l}\text { Number of bundled } \\
\text { conductors }\end{array}$ \\
\hline $8-9$ & 230 & 2 & 2 \\
$2-8$ & 400 & 2 & 3 \\
$2-7$ & 400 & 1 & 3 \\
$1-5$ & 400 & 2 & 3 \\
$8-18$ & 230 & 2 & 2 \\
$4-5$ & 230 & 2 & 2 \\
$7-16$ & 230 & 1 & 2 \\
$2-5$ & 230 & 2 & 2 \\
$7-17$ & 230 & 1 & 2 \\
$5-11$ & 230 & 1 & 2 \\
$6-13$ & 400 & 2 & 3 \\
$7-13$ & 230 & 1 & 2 \\
$6-9$ & 400 & 1 & 3 \\
$14-15$ & 400 & 1 & 2 \\
$11-18$ & 230 & 1 & 2 \\
\hline
\end{tabular}

Table 3. Expansion costs of the first configuration.

\begin{tabular}{ll}
\hline Expansion Cost of Substations & 0 \\
Expansion Cost of Lines & 36.751 million \$US \\
Total Expansion Cost of Network & 36.751 million \$US \\
\hline \multicolumn{2}{c}{ Table 4. Expansion costs of the second configuration. } \\
\hline Expansion Cost of Substations & 20.645 million \$US \\
Expansion Cost of Lines & 128.817 million \$US \\
Total Expansion Cost of Network & 149.462 million \$US \\
\hline
\end{tabular}

Total expansion costs of the both proposed configurations are shown in Figure 4.

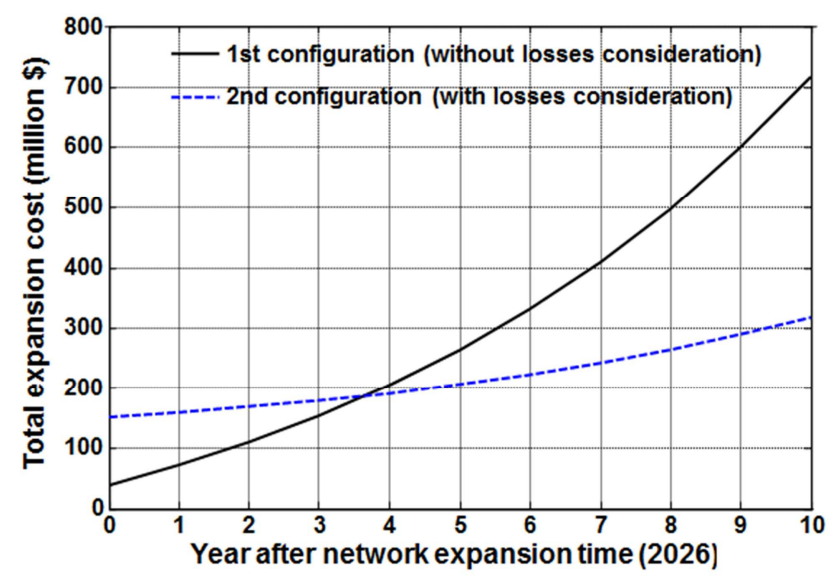

Figure 4. Total expansion cost for both configurations in run 1.

Also, rate of investment return of second configuration with respect to the first one is shown in Figure 5.

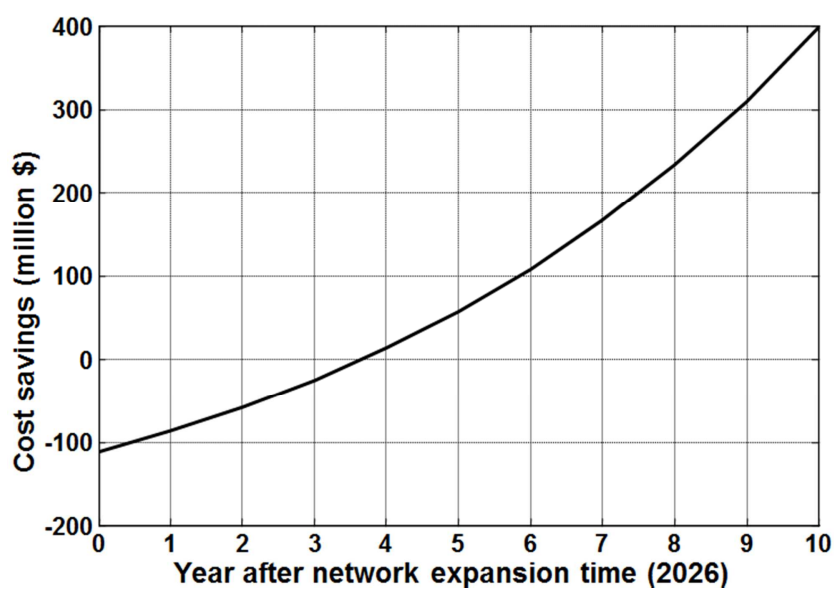

Figure 5. Capital return of the second configuration in run 1.

Run 2

Similar to previous section, the results (lines which should be added to the network up to the planning horizon year) are listed in Tables 5 and 6. Also, Tables 7 and 8 show the expansion costs.

Table 5. First configuration: without the losses.

\begin{tabular}{llll}
\hline Corr. & Voltage (kV) & $\begin{array}{l}\text { Number of new } \\
\text { circuits }\end{array}$ & $\begin{array}{l}\text { Number of bundled } \\
\text { conductors }\end{array}$ \\
\hline $6-8$ & 230 & 1 & 1 \\
$1-5$ & 230 & 1 & 2 \\
$4-5$ & 230 & 2 & 1 \\
$9-16$ & 230 & 1 & 1 \\
$2-13$ & 230 & 1 & 1 \\
$5-17$ & 230 & 1 & 1 \\
$4-18$ & 230 & 1 & 1 \\
\hline
\end{tabular}

Table 6. Second configuration: with the losses.

\begin{tabular}{llll}
\hline Corr. & Voltage (kV) & $\begin{array}{l}\text { Number of new } \\
\text { circuits }\end{array}$ & $\begin{array}{l}\text { Number of bundled } \\
\text { conductors }\end{array}$ \\
\hline $6-8$ & 400 & 2 & 3 \\
$7-8$ & 230 & 2 & 2 \\
$5-15$ & 400 & 1 & 3 \\
$1-5$ & 400 & 2 & 3 \\
$4-5$ & 400 & 2 & 3 \\
$17-12$ & 230 & 1 & 2 \\
$9-13$ & 400 & 2 & 3 \\
$1-11$ & 230 & 2 & 2 \\
$2-13$ & 400 & 2 & 3 \\
$6-9$ & 230 & 1 & 2 \\
$4-18$ & 400 & 1 & 3 \\
\hline
\end{tabular}

Table 7. Expansion costs of the first configuration.

\begin{tabular}{ll}
\hline Expansion Cost of Substations & 0 \\
Expansion Cost of Lines & 43.548 million \$US \\
Total Expansion Cost of Network & 43.548 million \$US \\
\hline
\end{tabular}

Table 8. Expansion costs of the second configuration.

\begin{tabular}{ll}
\hline Expansion Cost of Substations & 44.73 million \$US \\
Expansion Cost of Lines & 144.624 million \$US \\
Total Expansion Cost of Network & 189.354 million \$US \\
\hline
\end{tabular}


Total expansion cost of both proposed configurations is shown in Figure 6. Also, process of cost savings is shown in Figure 7.

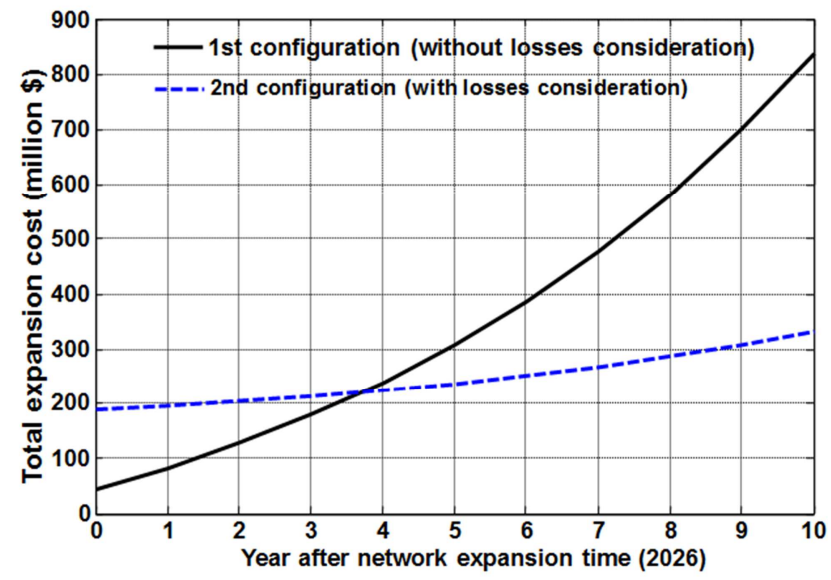

Figure 6. Total expansion cost for both configurations in run 2.

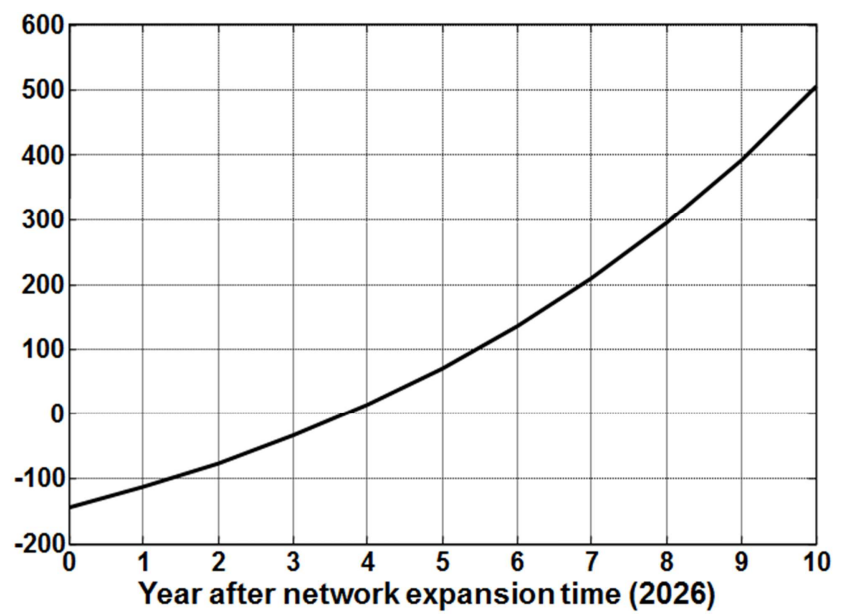

Figure 7. Capital return of the second configuration in run 1.

Run 3

The results are given in Tables 9 to 12 .

Table 9. First configuration: without the losses.

\begin{tabular}{llll}
\hline Corr. & Voltage (kV) & $\begin{array}{l}\text { Number of new } \\
\text { circuits }\end{array}$ & $\begin{array}{l}\text { Number of bundled } \\
\text { conductors }\end{array}$ \\
\hline $8-9$ & 230 & 1 & 1 \\
$1-5$ & 230 & 2 & 1 \\
$8-18$ & 230 & 1 & 1 \\
$5-7$ & 230 & 1 & 2 \\
$2-16$ & 230 & 1 & 1 \\
$1-3$ & 230 & 1 & 1 \\
$7-17$ & 230 & 1 & 1 \\
\hline
\end{tabular}

Table 10. Second configuration: with the losses.

\begin{tabular}{llll}
\hline Corr. & Voltage (kV) & $\begin{array}{l}\text { Number of new } \\
\text { circuits }\end{array}$ & $\begin{array}{l}\text { Number of bundled } \\
\text { conductors }\end{array}$ \\
\hline $8-9$ & 400 & 2 & 3 \\
$2-8$ & 230 & 2 & 2 \\
$2-7$ & 400 & 1 & 3 \\
$1-5$ & 400 & 2 & 3 \\
\hline
\end{tabular}

\begin{tabular}{llll}
\hline Corr. & Voltage (kV) & $\begin{array}{l}\text { Number of new } \\
\text { circuits }\end{array}$ & $\begin{array}{l}\text { Number of bundled } \\
\text { conductors }\end{array}$ \\
\hline $8-18$ & 230 & 2 & 2 \\
$5-7$ & 230 & 1 & 2 \\
$2-5$ & 400 & 2 & 3 \\
$13-15$ & 230 & 2 & 2 \\
$4-13$ & 230 & 2 & 2 \\
$11-13$ & 400 & 2 & 3 \\
$5-17$ & 230 & 1 & 2 \\
\hline
\end{tabular}

Table 11. Expansion costs of the first configuration.

\begin{tabular}{ll}
\hline Expansion Cost of Substations & 0 \\
Expansion Cost of Lines & 36.774 million \$US \\
Total Expansion Cost of Network & 36.774 million \$US \\
\hline
\end{tabular}

Table 12. Expansion costs of the second configuration.

\begin{tabular}{ll}
\hline Expansion Cost of Substations & 44.73 million \$US \\
Expansion Cost of Lines & 122.9 million \$US \\
Total Expansion Cost of Network & 167.63 million \$US \\
\hline
\end{tabular}

Also, total expansion cost of proposed configurations and process of cost savings are shown in Figures 8 and 9, respectively.

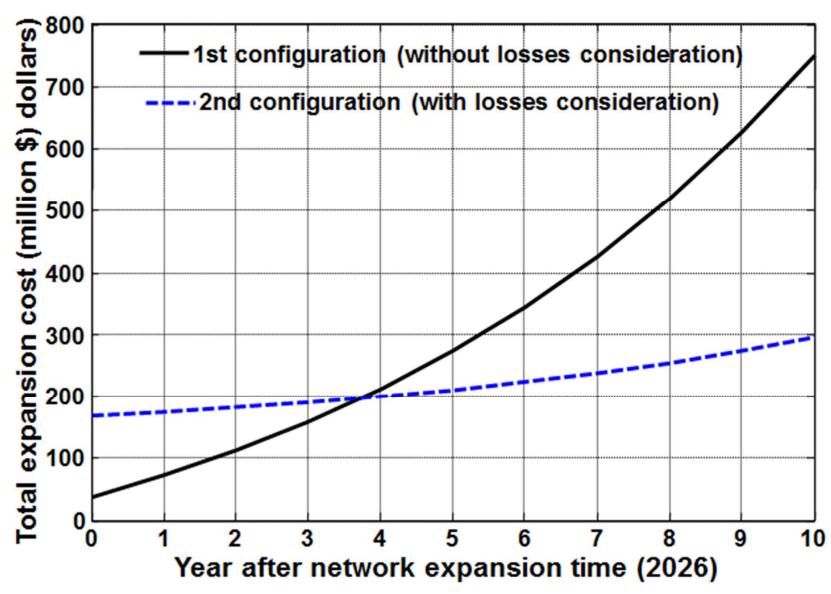

Figure 8. Total expansion cost for both configurations in run 3.

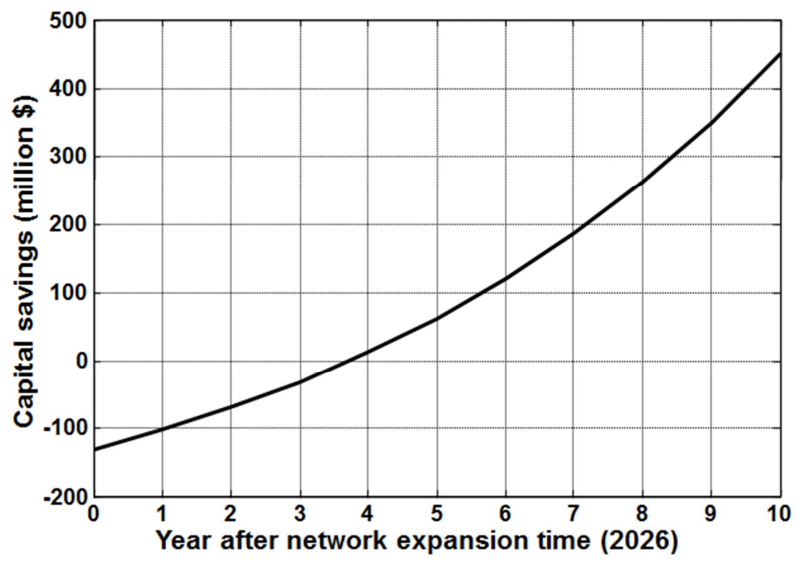

Figure 9. Capital return if the second configuration in run 3.

From Tables 3, 7 and 11, the expansion cost of substations is calculated zero, because voltage level of the proposed lines 
existed in their both first and end substations and therefore the expansion of substations was not necessary. Figures 4, 6 and 8 shows that total construction cost of second configuration is more than first one in the beginning, but it decreases under total construction cost of first configuration after about 4 years later (year 2021). Although it seems that the first configuration (all the lines are $230 \mathrm{kV}$ ) is less expensive, the second configuration is more economic if the network is studied considering the network losses after planning time.

The reason is that the annual network losses cost of the first configuration will become large in comparison with the second configuration about 4 years after planning horizon. In this way, total expansion cost of the first configuration will become more than the other one after about 4 years from the planning horizon.

Thus, the second configuration leads to cost savings after the $4^{\text {th }}$ year of the expansion time. Convergence process of the algorithm in run 3 is shown typically in Figure 10.

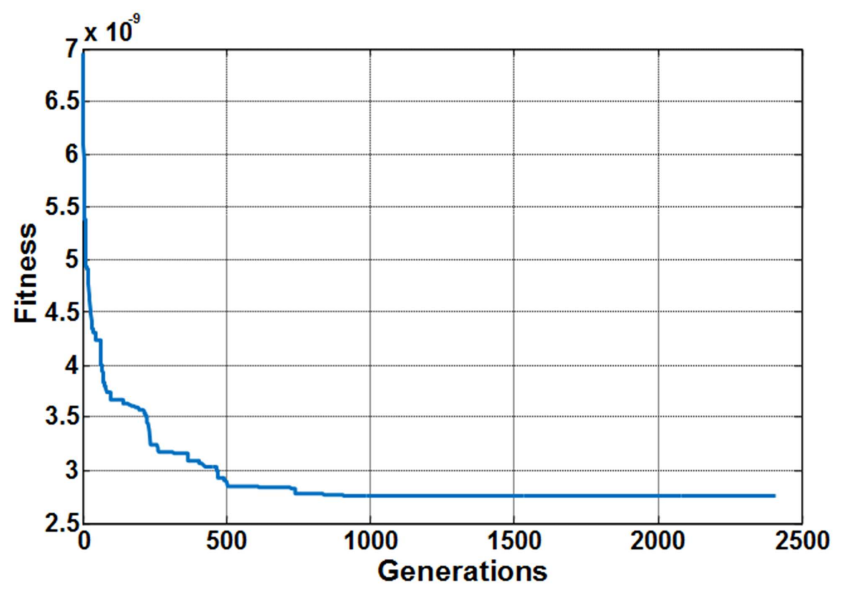

Figure 10. Convergence curve of the algorithm in run 3.

It should be noted that although construction cost of 400 $\mathrm{kV}$ lines is more than $230 \mathrm{kV}$ lines, but their total expansion cost (expansion and losses costs) is less than $230 \mathrm{kV}$ lines in long-run. In addition, the second configuration is overloaded later than first one. For example, in run 1, second one is overloaded 13 years after expansion time (planning horizon), whereas the first configuration is overloaded about 9 years after expansion time. Moreover, although lines with bundled conductors are more expensive than unbundled lines, these lines increase the network adequacy and decrease the network losses more than lines with single conductor.

In addition, construction of unbundled lines prevents increase in network dimension. For this, in this study, all transmission lines (both $400 \mathrm{kV}$ and $230 \mathrm{kV}$ ) were added to the network with their maximum number of bundled conductors ( 2 for $230 \mathrm{kV}$ and 3 for $400 \mathrm{kV}$ ).

\section{Conclusions}

In present paper, the static transmission network expansion planning was studied using the decimal codification genetic algorithm in a multi-voltage level transmission network containing bundled lines. According to simulation results, it was concluded that the network losses and voltage level of lines play important role in determination of network configuration and arrangement, because considering those in transmission expansion planning causes more $230 \mathrm{kV}$ and $400 \mathrm{kV}$ lines to install in the network. It can be said that total expansion cost of network (expansion costs and network losses cost) decreases and transmission lines are overloaded later when voltage level and network losses are considered in TNEP. Also, considering lines with bundled conductors instead of single conductor-lines in TNEP causes the transmission expansion planning problem to optimize more.

\section{Appendix}

\section{A. Test system data}

Tables 13- 17 shows the network's configuration, substation data, generation and loads information of the test system as given in Section 4. The construction costs of 230 and $400 \mathrm{kV}$ lines are listed in Tables 18 and 19.

Table 13. Network Configuration.

\begin{tabular}{lllll}
\hline Corr. & $\begin{array}{l}\text { length } \\
(\mathbf{k m})\end{array}$ & $\begin{array}{l}\text { Voltage } \\
(\mathbf{k V})\end{array}$ & $\begin{array}{l}\text { Number of } \\
\text { new circuits }\end{array}$ & $\begin{array}{l}\text { Number of bundled } \\
\text { conductors }\end{array}$ \\
\hline $6-1$ & 55 & 230 & 1 & 1 \\
$2-1$ & 14 & 230 & 2 & 1 \\
$9-6$ & 18 & 230 & 1 & 1 \\
$4-2$ & 83 & 230 & 1 & 1 \\
$14-5$ & 110 & 230 & 1 & 1 \\
$11-8$ & 65 & 230 & 2 & 1 \\
$11-10$ & 125 & 230 & 2 & 1 \\
$15-14$ & 139 & 230 & 1 & 1 \\
$12-1$ & 122 & 400 & 1 & 2 \\
$9-5$ & 100 & 230 & 1 & 1 \\
$6-5$ & 103 & 230 & 2 & 1 \\
$13-3$ & 105 & 400 & 1 & 2 \\
$4-3$ & 81 & 230 & 1 & 1 \\
$14-13$ & 44 & 230 & 2 & 1 \\
$12-10$ & 134 & 230 & 2 & 1 \\
$8-1$ & 75 & 230 & 2 & 1 \\
$7-6$ & 33 & 230 & 1 & 1 \\
$7-1$ & 22 & 230 & 1 & 1 \\
$5-16$ & 53 & 230 & 2 & \\
\hline & & & & 1 \\
\hline
\end{tabular}

Table 14. Arrangement of substations.

\begin{tabular}{llll}
\hline Substation & Voltage $(\mathbf{k V})$ & Substation & Voltage $(\mathbf{k V})$ \\
\hline 1 & $400 / 230$ & 10 & $230 / 132$ \\
2 & $230 / 132$ & 11 & $230 / 132$ \\
3 & $400 / 230$ & 12 & $230 / 132$ \\
4 & $230 / 63$ & 13 & $230 / 63$ \\
5 & $230 / 132$ & 14 & $400 / 230$ \\
6 & $230 / 132$ & 15 & $230 / 63$ \\
7 & $230 / 132$ & 16 & $230 / 20$ \\
8 & $230 / 132$ & 17 & $230 / 132$ \\
9 & $230 / 132$ & 18 & $230 / 132$ \\
\hline
\end{tabular}


Table 15. Generation and load data.

\begin{tabular}{llllll}
\hline Bus & $\begin{array}{l}\text { Load } \\
\text { (MW) }\end{array}$ & $\begin{array}{l}\text { Generation } \\
\text { (MW) }\end{array}$ & Bus & $\begin{array}{l}\text { Load } \\
\text { (MW) }\end{array}$ & $\begin{array}{l}\text { Generation } \\
\text { (MW) }\end{array}$ \\
\hline 1 & 378 & 715 & 10 & 0 & 134 \\
2 & 202 & 0 & 11 & 0 & 125 \\
3 & 42 & 0 & 12 & 288 & 256 \\
4 & 53 & 0 & 13 & 101 & 78 \\
5 & 45 & 0 & 14 & 60 & 46 \\
6 & 64 & 0 & 15 & 101 & 45 \\
7 & 88 & 0 & 16 & 0 & 11 \\
8 & 49 & 514 & 17 & 0 & 14 \\
9 & 70 & 0 & 18 & 0 & 79 \\
\hline
\end{tabular}

Table 16. $230 \mathrm{kV}$ lines' characteristics.

\begin{tabular}{llll}
\hline $\begin{array}{l}\text { Number of bundled } \\
\text { conductors }\end{array}$ & $\begin{array}{l}\text { Maximum } \\
\text { loading (MVA) }\end{array}$ & $\begin{array}{l}\text { Reactance } \\
\text { (p.u/Km) }\end{array}$ & $\begin{array}{l}\text { Resistance } \\
\text { (p.u/Km) }\end{array}$ \\
\hline 1 & 397 & $3.85 \mathrm{e}-4$ & $1.22 \mathrm{e}-4$ \\
2 & 794 & $2.84 \mathrm{e}-4$ & $2.44 \mathrm{e}-4$ \\
\hline
\end{tabular}

Table 17. $400 \mathrm{kV}$ lines' characteristics.

\begin{tabular}{llll}
\hline $\begin{array}{l}\text { Number of bundled } \\
\text { conductors }\end{array}$ & $\begin{array}{l}\text { Maximum } \\
\text { loading (MVA) }\end{array}$ & $\begin{array}{l}\text { Reactance } \\
\text { (p.u/Km) }\end{array}$ & $\begin{array}{l}\text { Resistance } \\
\text { (p.u/Km) }\end{array}$ \\
\hline 1 & 750 & $1.24 \mathrm{e}-4$ & $3.5 \mathrm{e}-5$ \\
2 & 1321 & $9.7 \mathrm{e}-5$ & $7 \mathrm{e}-5$ \\
3 & 1982 & $8.6 \mathrm{e}-5$ & $1.05 \mathrm{e}-4$ \\
\hline
\end{tabular}

Table 18. Construction cost of $230 \mathrm{kV}$ lines.

\begin{tabular}{lll}
\hline $\begin{array}{l}\text { Number of bundled } \\
\text { conductors }\end{array}$ & $\begin{array}{l}\text { Fix Cost } \\
\left(\times \mathbf{1 0}^{\mathbf{3}} \text { dollars }\right)\end{array}$ & $\begin{array}{l}\text { Variable Cost } \\
\left(\times \mathbf{1 0}^{\mathbf{3}} \text { dollars }\right)\end{array}$ \\
\hline 1 & 546.5 & 45.9 \\
2 & 546.5 & 63.4 \\
\hline
\end{tabular}

Table 19. Construction cost of $400 \mathrm{kV}$ lines.

\begin{tabular}{lll}
\hline $\begin{array}{l}\text { Number of bundled } \\
\text { conductors }\end{array}$ & $\begin{array}{l}\text { Fix Cost } \\
\left(\times \mathbf{1 0}^{\mathbf{3}} \text { dollars }\right)\end{array}$ & $\begin{array}{l}\text { Variable Cost } \\
\left(\times \mathbf{1 0}^{\mathbf{3}} \text { dollars }\right)\end{array}$ \\
\hline 1 & 1748.6 & 92.9 \\
2 & 1748.6 & 120.2 \\
\hline
\end{tabular}

\section{B. GA data}

Load growth $=8 \%$

Losses cost $=36.1(\$ / \mathrm{MWh})$

$L L_{\max }=50 \%$

\section{Acknowledgements}

This work was supported by the São Paulo Research Foundation (FAPESP), under grant 2016/12190-7.

\section{References}

[1] M. Mahdavi, H. Monsef, R. Romero "Reliability effects of maintenance on TNEP considering preventive and corrective repairs" IEEE Transactions on Power Systems, vol. 32, no. 5, pp.3768-3781, 2017.

[2] M. Mahdavi, H. Monsef, R. Romero "Reliability and economic effects of maintenance on TNEP considering line loading and repair" IEEE Transactions on Power Systems, vol. 31, no. 5, pp.3381-3393, 2016.
[3] H. Shayeghi, M. Mahdavi "Studying the effect of losses coefficient on transmission expansion planning using decimal codification based GA" International Journal on Technical and Physical Problems of Engineering, vol. 1, no. 1, pp. 58-64, 2009.

[4] H. Shayeghi, M. Mahdavi, H. Haddadian "DCGA basedtransmission network expansion planning considering network adequacy" International Journal of Electrical, Computer, Energetic, Electronic and Communication Engineering, vol. 2, no. 12 , pp. 2875-2880, 2008.

[5] A. Kazemi, S. Jalilzadeh, M. Mahdavi, H. Haddadian "Genetic algorithm-based investigation of load growth factor effect on the network loss in TNEP" 3rd IEEE Conference on Industrial Electronics and Applications, Singapore, vol. 1, pp. 764-769, June 2008.

[6] H. Shayeghi, M. Mahdavi "Application of PSO and GA for transmission network expansion planning" Book chapter in: Analysis, control and optimal operations in hybrid power systems, London, Springer, 2013, pp. 187-226.

[7] M. Mahdavi, H. Monsef, A. Bagheri "Dynamic transmission network expansion planning considering network losses, DG sources and operational costs-part 1: review and problem formulation" WULFENIA, vol. 19, no. 10, pp. 242-257, 2012.

[8] M. Mahdavi, H. Monsef, A. Bagheri "Dynamic transmission network expansion planning considering network losses, DG sources and operational costs-part 2: solution method and numerical results" WULFENIA, vol. 19, no. 10, pp. 258-273, 2012.

[9] M. Mahdavi, H. Monsef "Review of static transmission expansion planning" Journal of Electrical and Control Engineering, vol. 1, no. 1, pp. 11-18, 2011.

[10] T. Al-Saba, I. El-Amin "The application of artificial intelligent tools to the transmission expansion problem" Electric Power Systems Research, vol. 62, no. 2, pp. 117-126, 2002.

[11] A. Kimiyaghalam, M. Mahdavi, S. Jalilzadeh, A. Ashouri "Improved binary particle swarm optimization based TNEP considering network losses, voltage level, and uncertainty in demand" Journal of Artificial Intelligence in Electrical Engineering, vol. 1, no. 2, pp. 29-42, 2012.

[12] J. Contreras, F. F. Wu "A kernel-oriented algorithm for transmission expansion planning" IEEE Transactions on Power Systems, vol. 15, no. 4, pp. 1434-1440.

[13] M. Mahdavi, A. Bagheri, E. Mahdavi "Comparing efficiency of PSO with GA in transmission expansion planning considering network adequacy" WSEAS Transactions on Power Systems, vol. 7, no. 1, pp. 34-43, 2012.

[14] R. A. Gallego, R. Romero, A. J. Monticelli "Tabu search algorithm for network synthesis" IEEE Transactions on Power Systems, vol. 15 , no. 2, pp. 490-495, 2000.

[15] S. Binato, G. C. de Oliveira, J. L. Araujo "A greedy randomized adaptive search procedure for transmission expansion planning" IEEE Transactions on Power Systems, vol. 16, no. 2, pp. 247-253, 2001.

[16] S. Binato, M. V. F. Periera, S. Granville "A new Benders decomposition approach to solve power transmission network design Problems" IEEE Transactions on Power Systems, vol. 16, no. 2, pp. 235-240, 2001. 
[17] M. V. F. Periera, L. M. V. G. Pinto "Application of sensitivity analysis of load supplying capacity to interactive transmission expansion planning" IEEE Transactions on Power Apparatus and Systems, vol. PAS-104, pp. 381-389, 1985.

[18] R. Romero, R. A. Gallego, A. Monticelli "Transmission system expansion planning by simulated annealing" IEEE Transactions on Power Systems, vol. 11, no. 1, pp. 364-369, 1996.

[19] R. Romero, A. Monticelli "A hierarchical decomposition approach for transmission network expansion planning" IEEE Transactions on Power Systems, vol. 9, no. 1, pp. 373-380, 1994.

[20] M. Mahdavi, A. Bagheri "BPSO applied to TNEP considering adequacy criterion" American Journal of Neural Networks and Applications, vol. 4, no. 1, pp. 1-7, 2018.

[21] M. Mahdavi, H. Monsef, A. Bagheri "Lines loading optimization in transmission expansion planning based on binary PSO algorithm" i-manager's Journal on Information Technology, vol. 1, no. 1, pp. 24-32, 2012.

[22] M. Mahdavi, E. Mahdavi "Transmission expansion planning considering network adequacy and investment cost limitation using genetic algorithm" World Academy of Science, Engineering and Technology, vol. 5, no. 8, pp: 1-5, 2011.

[23] R. C. G. Teive, E. L. Silva, L. G. S. Fonseca "A cooperative expert system for transmission expansion planning of electrical power systems" IEEE Transactions on Power Systems, vol. 13, no. 2, pp. 636-642, 1998.

[24] J. Yen, Y. Yan, J. Contreras, P. C. Ma, F. F. Wu, "Multi-agent approach to the planning of power transmission expansion" Decision Support Systems, vol. 28, no. 3, pp. 279-290, 2000.

[25] K. Yoshimoto, K. Yasuda, R. Yokoyama "Transmission expansion planning using neuro-computing hybridized with genetic algorithm" IEEE International conference on Evolutionary Computation, Australia, vol. 1, pp. 126-131, 1995.

[26] H. Shayeghi, M. Mahdavi "Optimization of transmission lines loading in TNEP using decimal codification based GA" International Journal of Electrical, Computer, Energetic, Electronic and Communication Engineering, vol. 2, no. 2, pp. $1-18,2008$

[27] M. Mahdavi, E. Mahdavi "Evaluating the effect of load growth on annual network losses in TNEP considering bundle lines using DCGA" International Journal on Technical and Physical Problems of Engineering, vol. 3, no. 4, pp. 1-9, 2011.

[28] S. Jalilzadeh, A. Kimiyaghalam, M. Mahdavi, A. Ashouri "STNEP considering voltage level and uncertainty in demand using IABPSO" International Review of Electrical Engineering, vol. 7, no. 4, pp. 5186-5195, 2012.

[29] A. Kimiyaghalam, M. Mahdavi, A. Ashouri, H. Soheil "Transmission expansion planning considering uncertainty in fuel price using DABC" The 9th International Energy Conference, pp. 1-13, 2013.

[30] A. M. L. Silva, L. S. Rezende, L. A. F. Manso, L. C. Resende "Reliability worth applied to transmission expansion planning based on ant colony system" International Journal of Electrical Power \& Energy Systems, vol. 32, pp. 1077-1084, 2010.

[31] H. Shayeghi, H. Hosseini, A. Shabani, M. Mahdavi "GEP considering purchase prices, profits of IPPs and reliability criteria using hybrid GA and PSO" International Journal of Electrical, Computer, Energetic, Electronic and Communication Engineering, vol. 2, no. 12, pp. 2875-2880, 2008.

[32] M. Mahdavi, R. Romero "Transmission system expansion planning based on LCC criterion considering uncertainty in VOLL using DCGA" 32th International Power System Conference, pp. 1-7, 2017.

[33] M. Khodayari, M. Mahdavi, H. Monsef "Simultaneous scheduling of energy \& spinning reserve considering customer and supplier choice on reliability" 19 th Iranian Conference on Electrical Engineering, Iran, pp. 491-496, May 2011.

[34] M. Mahdavi, H. Monsef, A. Bagheri "Transmission lines loading enhancement using ADPSO approach" International Journal of Computer, Electrical, Automation, Control and Information Engineering, vol. 4, no. 3, pp. 556-561, 2010.

[35] A. Kazemi, H. Haddadian, M. Mahdavi "Transmission network adequacy optimization using genetic algorithm" 5th International Conference on Electrical and Electronics Engineering, pp. 1-5, 2007.

[36] S. Jalilzadeh, A. Kazemi, M. Mahdavi, H. Haddadian "Transmission expansion planning considering voltage level and network loss using genetic algorithm" 5th International Conference on Electrical and Electronics Engineering, pp. 1$5,2007$.

[37] H. Shayeghi, M. Mahdavi "Genetic algorithm based studying of bundle lines effect on network losses in transmission network expansion planning" Journal of Electrical Engineering, vol. 60, no. 5, pp. 237-245, 2009.

[38] S. Jalilzadeh, H. Shayeghi, M. Mahdavi, and H. Haddadian "A GA based transmission network expansion planning considering voltage level, network losses and number of bundle lines" American Journal of Applied Sciences, vol. 6, no. 5, pp. 987-994, 2009.

[39] J. Aghaei, N. Amjady, A. Baharvandi, M. A. Akbari "Generation and transmission expansion planning: MILPbased probabilistic model" IEEE Transactions on Power Systems, vol. 29, no. 4, pp. 1592-1601, 2014.

[40] S. T. Y. Lee, K. L. Hocks, H. Hnyilicza "Transmission expansion of branch and bound integer programming with optimal cost capacity curves" IEEE Transactions on Power Apparatus and Systems, vol. PAS-93, no. 5, pp. 1390-1400, 1970.

[41] A. S. D. Braga, J. T. Saraiva "A multiyear dynamic approach for transmission expansion planning and long-term marginal costs computation" IEEE Transactions on Power Systems, vol. 20, no. 3, pp. 1631-1639, 2005.

[42] H. Shayeghi, S. Jalilzadeh, M. Mahdavi, H. Hadadian "Role of voltage level and network losses in TNEP solution" Journal of Electrical Systems, vol. 5, no. 3, pp. 1-18, 2009.

[43] A. Arabali, M. Ghofrani, M. Etezadi-Amoli, M. S. Fadali, and M. Moeini-Aghtaie, "A multi-objective transmission expansion planning framework in deregulated power systems with wind generation" IEEE Trans. Power Syst., vol. 29, no. 6, pp. 3003-3011, 2014.

[44] B. Alizadeh and S. Jadid "A dynamic model for coordination of generation and transmission expansion planning in power systems" Electric Power System Research, vol. 65, no. 2, pp. 408-418, 2015. 
[45] S. Jalilzadeh, A. Kazemi, M. Mahdavi, H. Haddadian "TNEP considering voltage level, network losses and number of bundle lines using GA" Third International Conference on Electric Utility, Deregulation, Restructuring and Power Technologies, pp. 1580-1585, April 2008.
[46] M. Mahdavi, C. Sabillón, M. Ajalli, H. Monsef, R. Romero “A real test system for power system planning, operation, and reliability" Journal of Control, Automation and Electrical Systems, vol. 29, no. 2, pp. 192-208, 2018. 